\title{
Social obstetrics: non-local expectant mothers admitted through accident and emergency department in a public hospital in Hong Kong
}

\author{
WK Yung, Winnie Hui, YT Chan, TK Lo, SM Tai, C Sing, YY Lam, CM Lo, WL Lau, WC Leung *
}

\section{A B S T R A C T}

Objectives: To review the pregnancy outcomes of non-booked, non-local pregnant women delivering in Kwong Wah Hospital via admission to the Accident and Emergency Department 1 year after the announcement by the Hospital Authority to stop antenatal booking for non-eligible persons; and to perform a literature review of local studies about non-eligible person deliveries over the last decade.

Design: Case series.

Setting: A public hospital in Hong Kong.

Participants: All women who held the People's Republic of China passport or the two-way permit and those non-eligible persons whose spouses were Hong Kong Identity Card holders, who delivered in Kwong Wah Hospital from 1 April 2011 to 31 March 2012.

Results: Overall, 219 women who were non-eligible persons delivered 221 live births during the study period. Compared with the annual statistics of Kwong Wah Hospital in 2011, non-local mothers were of higher parity; more likely to have hypertensive disease (including pre-eclamptic toxaemia), preterm deliveries (ie at $<37$ weeks), babies needing admission to the special care baby unit, and macrosomic babies (ie weighing $>4.0 \mathrm{~kg}$ ). The rates of induction of labour and caesarean section were lower in this group. There was no significant difference in the maternal

This article was published on 9 May 2014 at www.hkmj.org. and neonatal outcomes between women who had no booking and those who had a booking in another Hospital Authority or private hospital. There were

many incidents of near-miss obstetric complications or suboptimally managed obstetric conditions due to lack of well-structured and continuous antenatal care in this group of non-eligible persons.

Conclusion: Non-eligible person delivering babies in Hong Kong has become a social obstetrics phenomenon. Despite the introduction of policies, reduction in the number of deliveries (quantity) did not improve the obstetric outcomes (quality). Health care professionals should continue to be prepared for managing the potential near-miss clinical complications in this group of 'travelling mothers'.

\section{Hong Kong Med J 2014;20:213-21 \\ DOI: 10.12809/hkmj134181}

${ }^{1}$ WK Yung, MB, BS, FHKAM (Obstetrics and Gynaecology)

${ }^{1}$ W Hui, MB, BS

${ }^{1}$ YT Chan, MB, BS, MRCOG

${ }^{1}$ TK Lo, FHKAM (Obstetrics and Gynaecology)

${ }^{1} \mathrm{SM}$ Tai, BSc, MSc

${ }^{1} \mathrm{C}$ Sing, BSc, MSc

${ }^{2}$ YY Lam, MB, BS, FHKAM (Paediatrics)

${ }^{3}$ CM Lo, FRCP (Irel), FHKAM (Emergency Medicine)

${ }^{1}$ WL Lau, MB, BS, FRCOG

${ }^{1}$ WC Leung, MD, FHKAM (Obstetrics and Gynaecology)

1 Department of Obstetrics and Gynaecology

Department of Paediatrics

${ }^{3}$ Department of Accident and Emergency

Kwong Wah Hospital, 25 Waterloo Road, Hong Kong

* Corresponding author: leungwc@ha.org.hk

New knowledge added by this study

- Non-eligible person (NEP) delivery in Hong Kong has been a social obstetric phenomenon specific to this region (Hong Kong SAR) because of political circumstances. Despite the reduction in the quantity, these nonbooked deliveries continue to run a high risk of adverse obstetric outcomes due to difficulties experienced by the expectant mothers in accessing a well-structured obstetric service.

Implications for clinical practice or policy

- Regardless of the number of patient load, the NEP women remain potentially at risk of obstetric complications. Health care professionals should be prepared for managing the near-miss conditions.

\section{Introduction}

The influx of expectant mothers from Mainland China leading to overwhelming of the local obstetric and neonatal services has been a hot topic of discussion in the media in the past few years. In
2001, the Hong Kong Court of Final Appeal delivered a unanimous opinion by which Chong Fung-yuen, a Chinese baby born while his Mainland Chinese parents were in Hong Kong on two-way permits, was granted residency in Hong Kong. In addition, in 


\section{經香港一所公立醫院急症室分婏的非本地孕婦： 一個關乎產科的社會議題 \\ 翁惠娟、許詠詩、陳嫈紫、盧子健、戴倩明、忻珠、林琬瑜、 \\ 盧礎文、劉偉霖、梁永昌}

目的：隨着香港醫院管理局宣佈所有公立醫院無限期停止接受非符合 資格人士預約分娩的政策一年後，本文回顧於廣華醫院經急症室入院 分娩而未經預約的非本地孕婦的妊娠結果, 以及回顧過去十年有關非 符合資格人士入院分婏的本地研究。

設計：病例系列。

安排：香港一所公立醫院。

參與者：所有於2011年4月1日至2012年3月31日期間於廣華醫院分 娩, 並持中國護照或 $「$ 雙程證」以及配偶為香港身份證持有人的非符 合資格人士。

結果：研究期間共有 219 名非符合資格人士分娩 221 名活產兒。與廣華 醫院2011年的年度統計數據比較, 非本地產婦的經產次數較高, 亦有 較大機會有高血壓（包括先兆子疬毒血症）、早產（即少於 37 週） 嬰兒需入住嬰兒特別護理部和懷有巨大嬰兒（即體重多於4千克）。 與此同時, 她們的引產和剖腹生產率明顯較低。在醫院管理局轄下的 醫院或者於私家醫院有預約的產婦, 和沒有預約的產婦比較, 兩者的 產婦和新生兒結果並無顯著差異。非符合資格人士組別當中發現很多 產科險情併發症的事故發生, 或者由於缺乏良好計劃和持續的產前護 理以致妊娠未達最好結果。

結論：非本地孕婦在港分娩已成為一個社會議題。儘管政策出台, 減 少分娩數目（量）並未能改善妊娠結果（質）。醫護人員應繼續為非 本地產婦隨時出現的險情併發症作好準備。
2003, the Hong Kong SAR Government introduced the Individual Visit Scheme which allowed travellers from Mainland China to visit Hong Kong and Macao on an individual basis. Since the introduction of these policies, there has been a dramatic increase in the number of 'traveller' mothers delivering in Hong Kong. This 'birth tourism'-a travel to a country that practises birthright citizenship or permanent residency in order to give birth there, so that the child will be a citizen of the destination country-has significantly influenced the standard obstetric practice in Hong Kong, resulting in adverse pregnancy outcomes. We have described this phenomenon as social obstetrics. ${ }^{1-3}$

According to the Hospital Authority (HA) pay code, there are seven categories of non-eligible person (NEP). The categories of NE-2 (People's Republic of China passport or two-way permit holder '雙非' ) and NE-3 (NEP whose spouse is a Hong Kong Identity Card [HKID] holder '單非') contribute to the majority of NEP deliveries in public hospitals.

In 2005, the HA launched an obstetric package to limit the number of non-local women delivering in public hospitals. The charge was HK\$20000 for 3 days and 2 nights of hospital stay including delivery.
However, this policy did not discourage 'traveller' mothers from delivering in public hospitals. ${ }^{4}$

In February 2007, the HA launched a new obstetric package for non-local expecting mothers. This package charged almost double (HK\$39000) for the hospitalisation for 3 days and 2 nights. Those who have not booked were additionally charged.

Unfortunately, the growing number of NEP deliveries in HA hospitals outweighed the capacity of public obstetric and neonatal services. In 2010, there were about 88000 deliveries in the territory, of which $50 \%$ were by mainland mothers (Fig 1a). The total capacity of neonatal intensive care units (NICUs; about 100 beds) in Hong Kong can only support an annual delivery rate of $75000 .^{5}$ This resulted in the formation of Hong Kong Obstetric Service Concern Group in March 2011-to urge the Hong Kong SAR Government to take action in preventing the collapse of public obstetric and neonatal services. The first remedial measure was to stop accepting new antenatal booking in HA hospitals from 8 April 2011 till the end of the year. One year later, on 26 April 2012, HA announced that there was no booking quota for non-local expecting mothers as public service was prioritised for the Hong Kong citizens to meet the surge of childbirth in the Chinese year of 'Dragon'. The non-booked deliveries would be charged HK\$90000 for the 3-days-2-nights package. Lastly, the Government prohibited antenatal booking of non-local mothers in either public (for NE-2 and NE-3 categories) or private (for NE-2 category) sectors from 1 January 2013 onwards (Table $1^{6,7}$ ).

However, if a pregnant woman, regardless of her identity card status, attended the accident and emergency department (AED) of a public hospital, the doctor-on-duty would assess her condition and offer admission to the obstetric unit if medically indicated. The admission rate via AED through the years varied with the implementation of obstetric package and government policy (Fig 1b). In 2005, when the first obstetric package was launched, the admission through AED for delivery was high. The second package in 2007 encouraged antenatal booking, and, thus, the AED admission rate dropped thereafter. Since April 2011, HA stopped all antenatal bookings for NEP, as a result of which the total number of NEP deliveries decreased drastically; however, the proportion of AED admissions increased.

In Kwong Wah Hospital, antenatal booking for non-local mothers had been stopped since April 2011. The NEP deliveries in our unit were mainly through AED admission or transfer from another HA or private hospital.

This retrospective study reviewed the pregnancy conditions and outcomes of a cohort of non-booked, non-local women admitted via AED of Kwong Wah Hospital over a 1-year period. 


\section{Methods}

This study evaluated the demographics, peripartum events, and pregnancy outcomes of the non-local pregnant women (NE-2 and NE-3 categories) who were admitted through AED and who delivered in Kwong Wah Hospital from 1 April 2011 to 31 March 2012. This was the 1-year period after HA's announcement (on 8 April 2011) of stopping antenatal booking for non-local women. The birth registry record of Kwong Wah Hospital was reviewed. Women who delivered in the captioned period with no HKID number were identified. Clinical records of the subjects were retrieved from the central record unit. Only women in NE- 2 and NE-3 categories were recruited.

Clinical notes and electronic patient records of the subjects were reviewed. The pregnancy conditions studied included the presenting symptoms, antenatal complications, gestation at delivery, mode of delivery, intrapartum and postpartum complications, birth weight of babies, Apgar score, need for neonatal resuscitation, admission to NICU or special baby care unit, neonatal morbidities, congenital abnormalities, etc. Maternal and neonatal outcomes were further analysed according to their booking status before admission. The annual statistics of Kwong Wah Hospital 2011 were used as reference.

\section{Statistical analysis}

Skewed continuous variables and nearly normally distributed variables were presented as medians (interquartile ranges) and means ( \pm standard deviations [SDs]), respectively. Categorical data

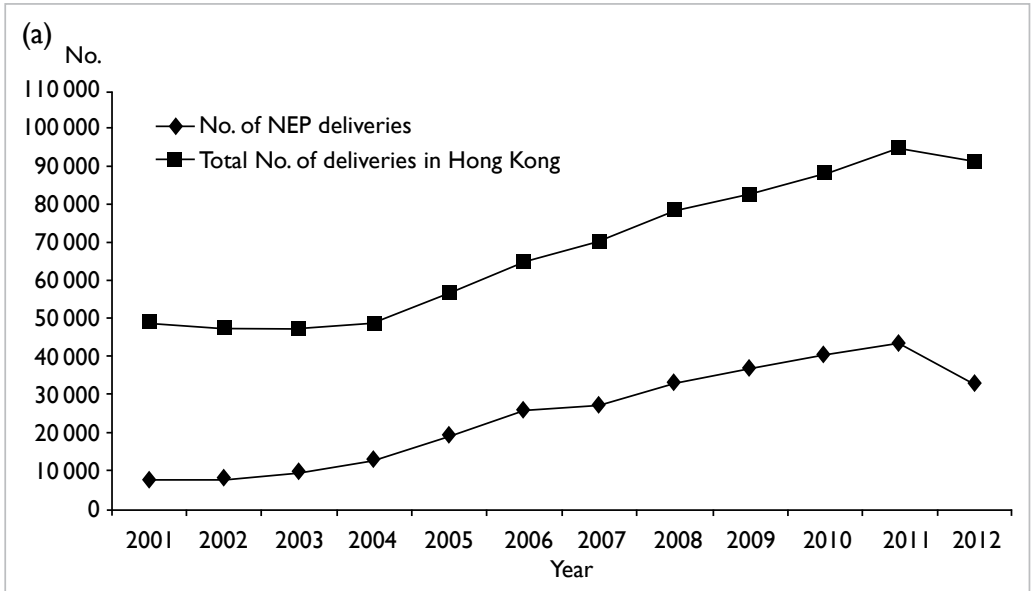

(b)

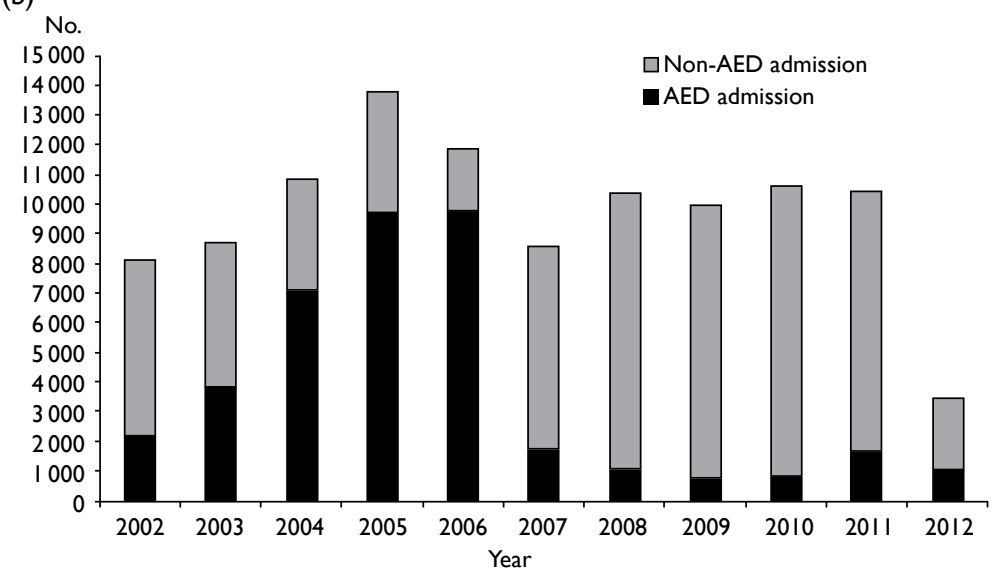

FIG I. (a) Number of non-eligible person (NEP) and total deliveries in Hong Kong (data from Hospital Authority). (b) Number of NEP deliveries in public hospitals via accident and emergency department (AED) and non-AED admissions (data from Hospital Authority)

TABLE I. Milestones in non-eligible person deliveries in Hospital Authority Obstetric Units

\begin{tabular}{|c|c|c|}
\hline Date & Milestones (all costs in HK\$) & Remarks \\
\hline 2001 & $\begin{array}{l}\text { The Court of Final Appeal's decision granting Chong Fung- } \\
\text { yuen (born while his parents were in HK on two-way permits) } \\
\text { permanent residency in HK. }\end{array}$ & $\begin{array}{l}\text { An increasing number of NEP mothers travelled from Mainland } \\
\text { China to HK to deliver their babies. }\end{array}$ \\
\hline 2005 & $\begin{array}{l}\text { HA NEP obstetric package: } \$ 20000 \text { for } 3 \text { days and } 2 \text { nights of } \\
\text { hospitalisation including delivery }+\$ 3300 \text { per extra day. }\end{array}$ & $\begin{array}{l}\text { Resulted in many non-booked NEP cases getting admitted } \\
\text { through } \mathrm{A} \& \mathrm{E}\left(\text { in } \mathrm{PMH}^{6} \text { ). }\right.\end{array}$ \\
\hline 1 Feb 2007 & $\begin{array}{l}\text { HA NEP obstetric package: } \$ 39000 \text { covering the first antenatal } \\
\text { visit, delivery and birth-related hospitalisation for } 3 \text { days and } 2 \\
\text { nights. Any additional clinic visit costed } \$ 700 \text { and any additional } \\
\text { day in hospital costed } \$ 3300 \text {. Those who came for deliveries but } \\
\text { had not booked would be charged } \$ 48000 \text {. The booking system } \\
\text { had been centralised with quota to avoid double-booking. }\end{array}$ & $\begin{array}{l}\text { Significantly reduced the number of non-booked cases but } \\
\text { still deferred the NEP mothers from having adequate antenatal } \\
\text { care (in } \mathrm{TMH}^{7} \text { ). }\end{array}$ \\
\hline 27 Mar 2011 & $\begin{array}{l}\text { Formation of the Hong Kong Obstetric Service Concern Group } \\
\text { (香港產科服務關注組). }\end{array}$ & $\begin{array}{l}\text { Voiced out and sought Government's support to solve this } \\
\text { social obstetrics problem. }\end{array}$ \\
\hline 8 Apr 2011 & HA stopped NEP bookings until end of 2011. & Non-booked NEP cases admitted through A\&E (present study). \\
\hline 26 Apr 2012 & HA stopped NEP bookings in the rest of 2012 . & Non-booked NEP cases admitted through A\&E. \\
\hline 13 May 2012 & $\begin{array}{l}\text { HA NEP charge: those who came for deliveries but had not } \\
\text { booked would be charged } \$ 90000 \text { (for } 3 \text { days and } 2 \text { nights). }\end{array}$ & Non-booked NEP cases admitted through A\&E. \\
\hline 1 Jan 2013 & $\begin{array}{l}\text { Government prohibited NEP bookings in both public (for NE-2 } \\
\text { and NE-3 categories) and private (for NE-2 category) hospitals. }\end{array}$ & Non-booked NEP cases admitted through A\&E. \\
\hline
\end{tabular}

Abbreviations: A\&E = accident and emergency department; HA = Hospital Authority; HK = Hong Kong SAR; NE-2 = People's Republic of China passport or two-way permit holder (隻非); NE-3 = non-eligible person whose spouse is a holder of Hong Kong identity card (單非); NEP = non-eligible person; $\mathrm{PMH}=$ Princess Margaret Hospital; $\mathrm{TMH}=$ Tuen Mun Hospital 
were presented as counts and percentages. MannWhitney $U$ test and independent sample $t$ test were used for comparison of medians and means, respectively. Pearson Chi squared test or Fisher's exact test were used for comparisons of frequencies, where appropriate. All analyses were performed with the Statistical Package for the Social Sciences (Windows version 16.0; SPSS Inc, Chicago [IL], US). A P value of less than 0.05 was regarded as statistically significant.

\section{Ethics approval}

Ethics approval for this study was granted by the Kowloon West Cluster Clinical Research Ethics Committee.

\section{Results}

A total of 219 maternities with delivery were identified during the study period. There were 221 live births (three pairs of twins) and one stillbirth. Two $(0.9 \%)$ pregnancies had been achieved by assisted reproduction. The mean $( \pm$ SD) age of women was $29.9 \pm 5.6$ years. Of the 219 women, $138(63.0 \%)$ were multiparous, 28 (12.8\%) of them had had one previous caesarean delivery, and one (0.5\%) had had two previous Caesarean sections. Overall, 139 (63.5\%) women were of NE-2 category and $53(24.2 \%)$ were of NE-3 category; the remaining 27 (12.3\%) did not provide information about their partners. A total of 138 (63.0\%) women had no booking in Hong Kong; 61 (27.9\%) women had antenatal booking in other HA hospitals; and 20 (9.1\%) women were booked in private hospitals but were referred or chose to deliver in HA hospitals.

The reasons of admission were as follows: show or with irregular uterine contraction $(n=98$, $44.7 \%)$, suspected rupture of membranes $(n=52$, $23.7 \%)$, active phase of labour $(\mathrm{n}=40,18.3 \%)$, and antenatal complications $(n=21,9.6 \%$; these included 10 cases of antepartum haemorrhage, five cases of preterm prelabour rupture of membranes, three cases of concerns on fetal wellbeing, two cases of maternal pre-eclampsia, and one case of threatened preterm labour). Five women admitted for postdate pregnancy requested for delivery. Two pregnancies were delivered in an ambulance and one on arrival to AED. One pregnancy was a stillbirth diagnosed after admission.

Routine antenatal blood tests (complete blood picture, blood group and Rhesus factor, immune status for hepatitis, syphilis, rubella, and human immunodeficiency virus) were performed in 147 (67.1\%) women. For the rest of the women, results of blood tests performed in another HA or private hospital were available via electronic or hard copies. Ultrasound assessment was performed for 126 (57.5\%) women before delivery.
Of the 219 pregnancies, 23 (10.5\%) were delivered before 37 weeks of gestation; two $(0.9 \%)$ pregnancies were delivered after 42 weeks of gestation. A total of $141(64.4 \%)$ women had spontaneous onset of labour; 32 (14.6\%) needed induction of labour, and $22(10.0 \%)$ needed augmentation of labour.

The majority of women $(n=182 ; 83.1 \%)$ had normal vaginal deliveries. Three $(1.4 \%)$ pregnancies required instrumental assistance. Caesarean section was performed in 13 (5.9\%) pregnancies after labour and $21(9.6 \%)$ without labour. The success rate of trial of vaginal delivery after one previous Caesarean section was $50 \%$. There was no uterine scar rupture in any case. Primary postpartum haemorrhage occurred in 13 (5.9\%) pregnancies. Seven (3.2\%) women required blood transfusion. The mean length of postnatal hospital stay was $2.0 \pm 0.4$ days.

Peripartum maternal complications were divided into mild and significant. Mild complications included seven cases of gestational hypertension, two cases of mild pre-eclampsia without magnesium sulphate treatment, three cases of gestational diabetes on insulin treatment, three cases of moderate thrombocytopenia (platelet count 50-100 $\left.\mathrm{x} 10^{9} / \mathrm{L}\right)$, five cases of retained placenta requiring surgical exploration, five cases of postpartum haemorrhage managed by medical therapy, three cases of post-delivery urinary retention, and five cases of postpartum fever. Significant complications included six cases of severe pre-eclampsia requiring magnesium sulphate treatment, two cases of placenta abruptio, two cases of major placenta praevia type IV, one case of massive primary postpartum haemorrhage requiring surgical intervention, and two cases of severe thrombocytopenia (platelet count $\left.<50 \times 10^{9} / \mathrm{L}\right)$.

During the study period, there were 121 (54.8\%) male and $100(45.2 \%)$ female live births. The mean birth weight was $3.3 \pm 0.5 \mathrm{~kg}$. There were $19(8.7 \%)$ babies with low birth weight $(<2.5 \mathrm{~kg}) ; 13$ (5.9\%) were macrosomic $(>4.0 \mathrm{~kg})$. Two babies required neonatal resuscitation. The admission rates to the NICU and special care baby unit (SCBU) were 3.7\% and $43.8 \%$, respectively. Overall, 15 (6.8\%) babies had minor congenital abnormalities. Three (1.4\%) had major abnormalities, including one ventricular septal defect, one atrial septal defect, and one bilateral congenital cataract. Apart from congenital problems, 51 babies had neonatal jaundice requiring phototherapy, 22 had respiratory complications, 22 had infection episodes, five had electrolyte disturbance, three had birth trauma, three had congenital hypothyroidism, three had hypoglycaemia, one had hypothermia, one had polycythaemia, one had anaemia requiring blood transfusion, one had neonatal autoimmune thrombocytopenia requiring intravenous immunoglobulin treatment, and one 
had neurological complications. The composite neonatal morbidity rate was $39.8 \%$.

The pregnancy outcomes of the study cohort were compared with the annual statistics (2011) of Kwong Wah Hospital, as shown in Table 2. Nonlocal mothers were of higher parity; more likely to have hypertensive disease (including pre-eclamptic toxaemia), preterm delivery ( $<37$ weeks), babies requiring admission to SCBU, and macrosomic babies $(>4.0 \mathrm{~kg})$. The rate of induction of labour and caesarean section was lower in this group.

We also analysed the maternal and neonatal outcomes based on their antenatal booking before admission (ie no booking versus booking in other HA or private hospitals). We found that there was no significant difference in maternal and neonatal outcomes between the two groups. The results are shown in Table 3.

\section{Discussion}

Standard obstetric practice is influenced by social behaviour such as 'birth tourism' resulting in adverse pregnancy outcomes; we have described this phenomenon as social obstetrics. ${ }^{1-3}$ Some women came because they wanted to evade the 'onechild' policy of Mainland China. This was reflected in our study which showed that $63 \%$ of the NEP mothers were multiparous versus $45 \%$ from the hospital annual statistics. The higher proportion of multiparity also explained the lower rate of labour induction and caesarean delivery in the study group. On the other hand, the significantly higher rates of preterm delivery, hypertensive disease, macrosomic babies, and SCBU admission suggest that the NEP mothers belonged to a high-risk group.

In this study cohort, $63.5 \%$ of women belonged to the NE-2 category. Their travelling permit only allowed a short period of stay. In principle, there could be shared care between Hong Kong and Mainland China; in reality, this form of shared care is often suboptimal because of the differences in clinical practice and culture between the two places. Some mothers could not make antenatal booking in Mainland China under the 'one-child' policy. Serious conditions may be detected for the first time during an emergency admission. ${ }^{8}$ This largely endangers the health of mothers and babies. We have chosen six typical cases for illustrating this issue (Table 4-12).

Over the years, two local studies have been published on the pregnancy outcomes of non-local expectant mothers delivering in public hospitals in Hong Kong., ${ }^{6,7}$ Yuk and Wong ${ }^{6}$ from Princess

TABLE 2. Comparison of pregnancy outcomes between the non-booked, non-local women and the $\mathrm{KWH}$ annual statistics in $20 \mathrm{II}$

\begin{tabular}{|c|c|c|c|}
\hline \multirow[t]{2}{*}{ Pregnancy outcome } & \multicolumn{2}{|c|}{ No. (\%) } & \multirow[t]{2}{*}{$P$ value } \\
\hline & NEP 2011-2012 $(n=219)$ & KWH annual statistics $(n=5862)$ & \\
\hline Primigravida & $81(37.0)$ & $3224(55.0)$ & $<0.001$ \\
\hline Multiple pregnancy & $3(1.4)$ & $89(1.5)$ & 0.860 \\
\hline Preterm (<37 weeks) & $23(10.5)$ & $353(6.0)$ & 0.011 \\
\hline Post-term (>42 weeks) & $2(0.9)$ & $2(0.03)$ & 0.224 \\
\hline Induction of labour & $32(14.6)$ & $1539(26.3)$ & $<0.001$ \\
\hline Instrumental delivery & $3(1.4)$ & $202(3.4)$ & 0.139 \\
\hline Caesarean section & $34(15.5)$ & $1267(21.6)$ & 0.038 \\
\hline Primary PPH & $13(5.9)$ & $238(4.1)$ & 0.231 \\
\hline Maternal hypertensive disorder (including PET and eclampsia) & $15(6.8)$ & $99(1.7)$ & $<0.001$ \\
\hline Placenta praevia & $3(1.4)$ & $92(1.6)$ & 0.815 \\
\hline Placenta abruptio & $2(0.9)$ & $9(0.2)$ & 0.074 \\
\hline DM/GDM on insulin & $3(1.4)$ & $42(0.7)$ & 0.480 \\
\hline Stillbirth & $1(0.5)$ & $18(0.3)$ & 0.697 \\
\hline Neonatal death & 0 & $4(0.1)$ & 0.699 \\
\hline Low birth weight $(<2.5 \mathrm{~kg})$ & $19(8.7)$ & $488(8.3)$ & 0.952 \\
\hline Macrosomia $(>4.0 \mathrm{~kg})$ & $13(5.9)$ & $158(2.7)$ & 0.008 \\
\hline AS $\leq 6$ at 1 minute & $8(3.7)$ & $154(2.6)$ & 0.477 \\
\hline AS $\leq 6$ at 5 minutes & $1(0.5)$ & $23(0.4)$ & 0.882 \\
\hline NICU admission & $8(3.7)$ & $165(2.8)$ & 0.445 \\
\hline SCBU admission & $96(43.8)$ & $1904(32.5)$ & $<0.01$ \\
\hline
\end{tabular}

Abbreviations: $\mathrm{AS}=$ Apgar score; DM = diabetes mellitus; GDM = gestational diabetes mellitus; $\mathrm{KWH}=$ Kwong Wah Hospital; NEP = non-eligible person; $\mathrm{NICU}=$ neonatal intensive care unit; $\mathrm{PET}=$ pre-eclamptic toxaemia; $\mathrm{PPH}=$ postpartum haemorrhage; $\mathrm{SCBU}=$ special care baby unit 
TABLE 3. Maternal and neonatal outcomes of pregnancies based on antenatal booking before admission

\begin{tabular}{|c|c|c|c|}
\hline \multirow[t]{2}{*}{ Maternal outcome } & \multicolumn{2}{|c|}{ No. (\%) } & \multirow[t]{2}{*}{$P$ value } \\
\hline & No booking $(n=138)$ & $\begin{array}{l}\text { Booked (private or other HA } \\
\text { hospitals) [n=81] }\end{array}$ & \\
\hline NSD & $116(84.1)$ & $66(81.5)$ & 0.731 \\
\hline Instrumental & $2(1.4)$ & $1(1.2)$ & 0.731 \\
\hline LSCS & $20(14.5)$ & $14(17.3)$ & 0.582 \\
\hline Primary PPH & $6(4.3)$ & $7(8.6)$ & 0.194 \\
\hline Blood transfusion & $4(2.9)$ & $3(3.7)$ & 0.744 \\
\hline Mild morbidities* & $19(13.8)$ & $11(13.6)$ & 0.630 \\
\hline \multirow[t]{2}{*}{ Significant morbidities $†$} & $6(4.3)$ & $6(7.4)$ & 0.630 \\
\hline & \multicolumn{2}{|c|}{ No. (\%) } & \\
\hline Neonatal outcome & No booking $(n=138)$ & $\begin{array}{l}\text { Booked (private or other HA } \\
\text { hospitals) [n=83] }\end{array}$ & $P$ value \\
\hline Prematurity $<34$ weeks & $2(1.4)$ & $2(2.4)$ & 0.599 \\
\hline Low birth weight $<2.5 \mathrm{~kg}$ & $13(9.4)$ & $6(7.2)$ & 0.727 \\
\hline Neonatal resuscitation & 0 & $2(2.4)$ & 0.067 \\
\hline NICU admission & $5(3.6)$ & $3(3.6)$ & 0.997 \\
\hline SCBU admission & $62(44.9)$ & $34(41.0)$ & 0.565 \\
\hline NNJ requiring $\mathrm{PT}$ & $32(23.2)$ & $19(22.9)$ & 0.960 \\
\hline Respiratory complications & $15(10.9)$ & $7(8.4)$ & 0.946 \\
\hline Sepsis or local infection & $15(10.9)$ & $7(8.4)$ & 0.558 \\
\hline Neurological complications & 0 & $1(1.2)$ & 0.196 \\
\hline Birth trauma & $3(2.2)$ & 0 & 0.176 \\
\hline Major congenital disorders & $1(0.7)$ & $2(2.4)$ & 0.210 \\
\hline Others $\ddagger$ & $17(12.3)$ & $6(7.2)$ & 0.230 \\
\hline Composite morbidities & 59 (42.8) & 29 (34.9) & 0.250 \\
\hline
\end{tabular}

Abbreviations: HA = Hospital Authority; LSCS = lower-segment caesarean section; NICU = neonatal intensive care unit; NNJ = neonatal jaundice; NSD = normal spontaneous delivery; $\mathrm{PPH}=$ postpartum haemorrhage; $\mathrm{PT}$ = phototherapy; $\mathrm{SCBU}=$ special care baby unit

* Mild morbidities included pre-existing or gestational hypertension, mild pre-eclampsia, pre-existing or gestational diabetes on insulin therapy, mild-to-moderate thrombocytopenia (platelet 50-100 $\times 10^{9} / \mathrm{L}$ ), primary postpartum haemorrhage given medical therapy only, postpartum urinary retention, and puerperal fever

† Significant morbidities included severe pre-eclampsia requiring magnesium sulphate, placenta abruptio, placenta praevia, primary postpartum haemorrhage requiring surgical treatment, and moderate-to-severe thrombocytopenia (platelet $<50 \times 10^{9} / \mathrm{L}$ )

‡ Others: abnormal thyroid function, deranged electrolytes, hypoglycaemia, hypothermia, polycythaemia, anaemia requiring transfusion, and neonatal autoimmune thrombocytopenia

Margaret Hospital conducted a study between 2004 and 2006 when the HA launched the first obstetric package to the non-local women in 2005. During that period, around 35\% of deliveries in Princess Margaret Hospital were attributed to non-local Chinese women. The proportion increased significantly from $27 \%$ in 2004 to $43 \%$ in 2006 . Compared with local Chinese women, the NEPs were younger, of lower parity, and had fewer pre-existing medical problems. However, they had higher chances of unplanned vaginal breech deliveries, severe hypertensive disease in pregnancy, pre-eclampsia, delivering before arrival to hospital, and giving birth postterm ( $\geq 42$ weeks). Neonatal complications including preterm birth, stillbirth, and neonatal death were also more frequent among the NEP women. In fact, the first obstetric package was proposed mainly to charge the NEPs for delivery service expenses; it did not cover the antenatal service. This resulted in many of them coming to the hospital only for giving birth. Many of them came at the 'last-minute' to reduce the length of hospital stay due to financial concerns. This created a heavy burden on the public obstetric services and increased the risk of adverse pregnancy outcomes.

The second obstetric package in 2007 encouraged the NEP mothers to receive proper antenatal checkup. Lam ${ }^{7}$ from Tuen Mun Hospital conducted a study from 2006 to 2008 investigating the impact of the package on public obstetric services and pregnancy outcomes. It was observed that the number of NEP deliveries decreased from 
TABLE 4. Cases to illustrate social obstetrics phenomenon ${ }^{9-12}$

Case Comments

\section{Major placenta praevia/accreta-compromised care}

A 37-year-old woman with a history of LSCS was admitted through AED at 31 weeks' gestation for mild antepartum haemorrhage. Assessment showed major placenta praevia. Prophylactic steroid was given. She was warned about the high-risk pregnancy and delivery by caesarean section under careful planning with multidisciplinary involvement. She was not eligible for antenatal booking in our unit (NE-2 category) so she was discharged after bleeding stopped. The woman admitted again through AED at 37 weeks' gestation for vaginal spotting. Antepartum haemorrhage was not confirmed on assessment. The couple strongly requested to stay for delivery. In view of the potential placenta accreta and high risk of massive bleeding, we liaised with anaesthetists and interventional radiologists for caesarean section and standby uterine artery embolisation at 38 weeks. Classical caesarean section was performed. The placenta was adherent and around one fifth of it was left behind in the uterus for conservative management. Uterine artery embolisation was performed. Blood loss was $1200 \mathrm{~mL}$. She was admitted to intensive care unit for postoperative care. She was discharged on day 7 and went back to Mainland China. Written information was given to her obstetrician in Mainland China. Six weeks after delivery, she was admitted to a hospital in Mainland China for heavy vaginal bleeding. Three months later, she returned to Hong Kong for follow-up. Menstruation returned and ultrasound showed a small $(1 \mathrm{~cm})$ shadow at lower uterine cavity of no clinical significance.
Major placenta praevia carries substantial risk of massive haemorrhage and maternal morbidity. In background of previous caesarean section, the risk of placenta accreta is an additional concern. Hysterectomy without placenta removal has been the traditional management of placenta accreta. However, this approach also carries significant maternal morbidities and is undesirable for women who want to preserve their fertility. There has been growing evidence on leaving placental tissue behind for conservative management. According to our unit's experience published recently as a case series, ${ }^{9}$ planned conservative management of placenta accreta is feasible with good outcome. Prerequisite of success includes careful preoperative planning, involvement of experienced personnel from different disciplines, and a highly dedicated team for postpartum follow-up. The behaviour of the retained placenta can be variable. Readmission rate is relatively high.

In this case, the woman admitted through AED for antepartum haemorrhage. It was fortunate that the bleeding was not heavy so that planned operation for placenta accreta was feasible. However, another hindrance was that she could not come back for regular follow-up because of the travelling visa. Liaison with obstetricians in Mainland China was possible but could be difficult due to the differences in medical language and usual practice. Nevertheless, the outcome in the patient was good under the unofficial joint care.

\section{Severe pre-eclampsia-delivered too late (near-miss)}

A 35-year-old woman delivered at a gestational age of $>42$ weeks. She had had one previous LSCS. She had undergone antenatal checkup in Mainland China in early gestation and the expected date of confinement had been confirmed. She travelled to Hong Kong in late second trimester and received no antenatal checkup thereafter. Her plan was to attend a public hospital on developing symptoms of labour. She did not seek medical advice despite passing her due date. She was admitted to Kwong Wah Hospital for irregular tightening at 42 weeks and 3 days of gestation. Examination and investigations on arrival revealed that she had high blood pressure $(>160 / 100 \mathrm{~mm} \mathrm{Hg}$ ) and proteinuria. Emergency LSCS was performed after stabilising maternal condition. Magnesium sulphate and antihypertensive drugs were given in the peripartum period. A baby girl weighing $2.99 \mathrm{~kg}$ was delivered in good condition. She was admitted to the neonatal unit for observation.

\section{Severe maternal thrombocytopenia with affected newborn (near-miss)}

A 20-year-old nulliparous woman was admitted to the labour ward at 38 weeks' gestation for show. She had no booking for delivery in Hong Kong. Antenatal blood test in a private hospital in her third trimester showed low platelet count $\left(42 \times 10^{9} / \mathrm{L}\right)$. No further investigation was performed. Urgent complete blood count showed severe thrombocytopenia $\left(18 \times 10^{9} /\right.$ L). Physicians, anaesthetists, and paediatricians were urgently consulted for joint care. The woman went into labour soon after admission. Four units of platelet concentrate were transfused in the peripartum period. A baby girl weighing $3.15 \mathrm{~kg}$ was delivered by normal vaginal route. Blood loss was $200 \mathrm{~mL}$. The baby suffered from neonatal autoimmune thrombocytopenia requiring intravenous immunoglobulin treatment. The presumptive diagnosis of the mother was ITP. She strongly requested discharge on postpartum day 2 and did not attend postnatal follow-up.
Pre-eclampsia is a common obstetric problem. The condition could be easily screened if pregnant women attend antenatal clinics regularly. It could be a dangerous condition to be missed. In our cohort, pre-eclampsia was diagnosed late because women did not attend structured antenatal care. They were diagnosed with severe pre-eclampsia only after their admission for other reasons (mostly symptoms of labour). In this case, apart from pre-eclampsia, the pregnancy was allowed to go post-term (42 weeks 3 days) without appropriate fetal monitoring. This is an unusual phenomenon under modern obstetric care. The standard practice would be delivery at 41 weeks for post-date and before 40 weeks for pre-eclampsia. Our unit had previously reported two cases of postmaturity-related perinatal mortality in non-local women who delivered at 42 weeks 6 days and 44 weeks' gestation. ${ }^{10}$

Abbreviations: AED = accident and emergency department; ITP = idiopathic thrombocytopenic purpura; LSCS = lower-segment caesarean section; NE-2 = People's Republic of China passport or two-way permit holder 
TABLE 4. (Cont'd)

4. Fetal distress requiring imminent delivery-but all NICUs were full (compromised care)

A 36-year-old G2P1 woman was referred by her private obstetrician for fetal monitoring of IUGR. She had booked in a private hospital for delivery. The latest examination at 32 weeks' gestation showed a severe IUGR fetus with absent end-diastolic flow on umbilical artery Doppler study. She attended the AED with a referral letter from private obstetrician. Repeat ultrasound examinations after admission showed similar findings. Steroid prophylaxis was given to hasten fetal lung maturity. Cardiotocogram showed reduced baseline variability and variable decelerations. Delivery was indicated and the baby had high chance of requiring intensive care. However, the NICU was full in Kwong Wah Hospital. We consulted all the neonatal units of other public hospitals in Hong Kong but no NICU bed was available. Eventually, the baby boy was delivered in Kwong Wah Hospital by emergency LSCS. He weighed $1.11 \mathrm{~kg}$. Apgar score was 4 at first minute and 8 at fifth minute. Cord blood $\mathrm{pH}$ was 6.98; base excess was -20.4 . Neonatal resuscitation was required at birth. The baby stayed in neonatal unit for 87 days. He had multiple morbidities such as neonatal jaundice, respiratory distress syndrome, pneumonia, acute intracranial haemorrhage, disseminated intravascular coagulopathy, hypoglycaemia, patent ductus arteriosus, and total parenteral nutrition-related cholestasis.

\section{Twin with one small-for-gestational-age fetus-high-risk} pregnancy without monitoring and delivery plan (near-miss)

A 21-year-old nulliparous woman carried DCDA twin pregnancy. She had no booking for delivery in Hong Kong. Her travelling visa expired when pregnancy got close to term. Therefore, she waited for the symptoms of labour and was admitted through the AED at 39 weeks and 4 days of gestation. The first twin was in cephalic presentation. Labour was augmented with syntocinon. Twin I was delivered by vacuum extraction for poor maternal effort. A baby boy weighing $2.73 \mathrm{~kg}$ was born in good condition. External cephalic version was performed on twin II. The second baby boy weighing $2.36 \mathrm{~kg}$ was born by spontaneous vaginal route. He was admitted to the neonatal unit for being asymmetrically small for gestational age. He also suffered from infection and hypoglycaemia.

\section{Undiagnosed GDM and intrauterine death-would structured antenatal care change the fate (missed)?}

A 34-year-old G3P1 woman was admitted through AED at 37 weeks' gestation for early symptoms of labour and reduced fetal movement. She had no booking for delivery in Hong Kong. She attended antenatal care in Mainland China at early gestation of pregnancy but did not have any follow-up after travelling to Hong Kong. On admission, the fetal heart could not be heard on doptone. Intrauterine death was confirmed by ultrasound scan. She went into labour soon after admission. A macerated stillbirth was born. The fetal parameters corresponded to 35-36 weeks' gestation. Investigation showed the woman had GDM and this was not known during her pregnancy. She was discharged on postpartum day 2 and did not return for follow-up.
Neonatal service had been under great tension during our study period. It was mainly due to the increase in total number of deliveries in the territory. This case provides a good illustration of the shortage of manpower and resources in NICU service. This leads to the formation of the Obstetric and Neonatal Service 'concern groups' to request the Hong Kong SAR Government to impose a policy to prevent the collapse of obstetric and neonatal services. In our study, the admission rate to the NICU and SCBU was $3.7 \%$ and $43.8 \%$, respectively. It was higher than the respective rates of $2.8 \%$ and $32.5 \%$ in the annual statistics.
Twin pregnancy carries high risk. Our unit has developed specialised clinic to provide structured individualised antenatal care. ${ }^{11}$ Regular ultrasound assessment is essential to assess fetal wellbeing because clinical assessment of uterine size is not reliable for multiple pregnancy. Data suggest that small fetus or growth discordance among twins increases the risk of neonatal morbidity. ${ }^{11}$ RCOG guidelines recommend DCDA twins to be delivered at 37 weeks' gestation. The mode of delivery should be individualised according to medical and obstetric assessments and the patient's preference..$^{12}$ In this case, the second twin was small-for-gestational-age and growth-discordant to the first twin. Despite the uneventful outcome, close fetal monitoring and earlier delivery should have been performed in this pregnancy.

Screening for GDM has been a standard in obstetric practice. Uncontrolled GDM increases the risk of intrauterine fetal death at third trimester. Women having GDM are advised dietary restriction and regular glucose monitoring. For some women, insulin therapy may be needed. If glucose control is suboptimal, fetal monitoring and earlier delivery should be considered. In this case, whether undiagnosed GDM increased the risk of fetal demise remains an unanswered question, but undoubtedly it was a preventable factor.

Abbreviations: $\mathrm{AED}=$ accident and emergency department; $\mathrm{DCDA}=$ dichorionic diamniotic; GDM = gestational diabetes mellitus; IUGR = intrauterine growth restriction; LSCS = lower-segment caesarean section; NICU = neonatal intensive care unit; RCOG = Royal College of Obstetricians and Gynaecologists; SCBU = special baby care unit

1868 to 1398 per year. The number of non-booked admissions through AED reduced. The rate of postterm pregnancies dropped from $3.2 \%$ to $1.8 \%$. The reason for fewer deliveries was a shift of patients to private obstetric services after setting the quota and raising the cost. Nevertheless, this obstetric package did not improve the admission behaviour and pregnancy outcomes.

Thanks to our HA and the Hong Kong SAR Government's policy of stopping NEP bookings altogether in HA Obstetric Units, the number of NEP deliveries during our study period (2011-2012) 
was significantly reduced and limited to non-booked cases admitted through AED (Fig 2). We observed that reduction in 'quantity' did not improve the 'quality' of care in this group of women. The admission pattern and pregnancy outcomes remained similar to those in previous local studies. We also observed that, although some women had prior 'booking' in other HA or private hospitals, their pregnancy outcomes were no better than the 'no booking' group (Table 3 ). One possible reason for this could be that their travelling permit hindered them from receiving the 'standard' antenatal care. It was difficult to measure the quality of the obstetric care received by the 'booked group' because of its heterogeneity. We have used case examples to illustrate how the common obstetric conditions could be 'near-miss' conditions or standard obstetric service could be compromised under this social obstetrics phenomenon. We foresee that the third obstetrics package introduced in 2012 is unlikely to make a significant improvement in pregnancy outcomes unless the NEP women attend a structured antenatal care like the local mothers do.

In our study, we compared the pregnancy outcomes of our NEP cohort admitted through A\&E $(n=219)$ with the general pregnant population from our annual statistics $(n=5862)$. This might introduce a pre-selection bias. Our NEP cohort was also limited by its relatively small number. In the study by Yuk and Wong, ${ }^{6}$ the pregnancy outcomes of the NEP cohort $(n=4657)$ were compared with those of the eligible-person cohort $(n=8655)$ from 2004 to 2006. In the study by Lam, ${ }^{7}$ the pregnancy outcomes of two NEP cohorts ( $n=1868$ in $2006 / 2007$ vs $n=1398$ in 2007/2008) were compared.

\section{Conclusion}

Non-local expectant mothers delivering babies in Hong Kong has become a classic social obstetrics phenomenon. There is nothing wrong with these mothers who would like to have their children to be born in Hong Kong and become permanent residents of Hong Kong. Not long ago, Hong Kong mothers wanted to give birth in the US or Canada so that their children could become citizens of those countries. The problem in Hong Kong is the large volume of pregnancies which has exceeded our obstetric and neonatal capacities, thus affecting the health care of our local pregnant mothers and neonates. Although our Government now prohibits NEP bookings in both public (for NE-2 and NE-3 categories) and private (for NE-2 category) hospitals, non-local expectant mothers continue to admit themselves through AED for deliveries. Health care professionals should continue to be prepared for managing these potential near-miss clinical situations arising from this social obstetrics phenomenon. We hope this paper serves as one of the historical records in literature for this social

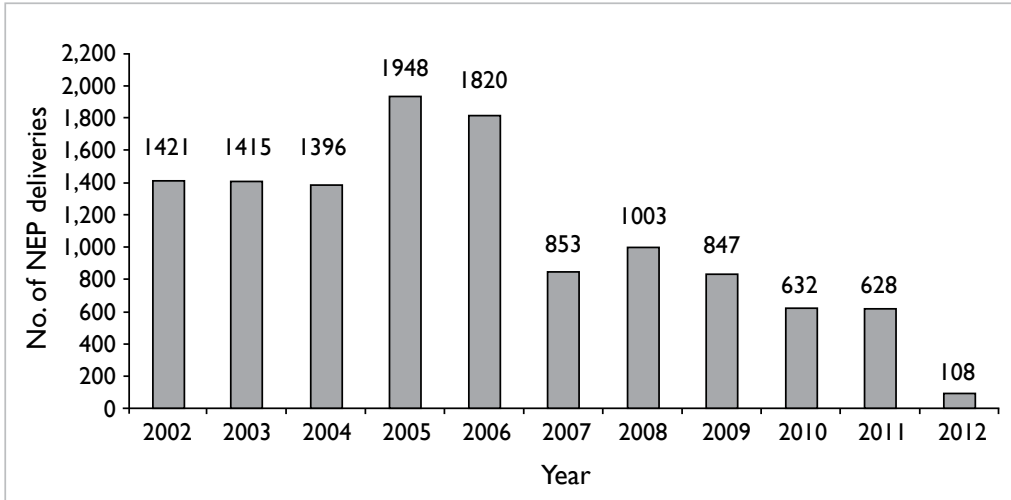

FIG 2. Number of non-eligible person (NEP) deliveries in Kwong Wah Hospital (data from Hospital Authority)

obstetrics phenomenon in the recent obstetric history of Hong Kong.

\section{References}

1. Leung WC. Social obstetrics-non-local expectant mothers delivering babies in Hong Kong. The Hong Kong Medical Diary 2009;14:13-4.

2. Leung WC, Lau WL. Cross-border families: transgression and dialogue [in Chinese]. Hong Kong: Red Publishing; 2008: 55-9.

3. Leung WC. Social obstetrics (cross-border pregnant women) [in Chinese]. Chiu MC, editor. Children, medicine, law: a comparative study of Greater China. Hong Kong: Roundtable Publishing; 2012: 40-8.

4. Au Yeung SK. Impact of non-eligible person deliveries in obstetric service in Hong Kong. Hong Kong J Gynaecol Obstet Midwifery 2006;6:41-4.

5. Leung TY, Lao T. Influx of mainland expectant mothers: a blessing or a curse? Hong Kong J Gynaecol Obstet Midwifery 2009;11:9-10.

6. Yuk JY, Wong S. Obstetrical outcomes among non-local Chinese pregnant women in Hong Kong. Hong Kong J Gynaecol Obstet Midwifery 2009;9:9-15.

7. Lam KD. Is the new obstetrics package for non-local pregnant women making a change? Hong Kong J Gynaecol Obstet Midwifery 2010;10:62-8.

8. Kwan WY, So CH, Chan WP, Leung WC, Chow KM. Reemergence of late presentations of fetal haemoglobin Bart's disease in Hong Kong. Hong Kong Med J 2011;17:434-40.

9. Lo TK, Yung WK, Lau WL, Law B, Lau S, Leung WC. Planned conservative management of placenta accretaexperience of a regional general hospital. J Matern Fetal Neonatal Med 2014;27:291-6.

10. Yung C, Liu K, Lau WL, Lam H, Leung WC, Chin R. Two cases of postmaturity-related perinatal mortality in nonlocal expectant mothers. Hong Kong Med J 2007;13:231-3.

11. Yung WK, Liu AL, Lai SF, et al. A specialised twin pregnancy clinic in a public hospital. Hong Kong J Gynaecol Obstet Midwifery 2012;12:21-32.

12. Liu AL, Yung WK, Lai SF, et al. Factors influencing the mode of delivery and associated pregnancy outcomes for twins: a retrospective cohort study in a public hospital. Hong Kong Med J 2012;18:99-107. 